\title{
Properties of alumina films prepared by metal-organic chemical vapour deposition at atmospheric pressure in the presence of small amounts of water
}

\author{
V.A.C. Haanappel, J.B. Rem, H.D. van Corbach, T. Fransen *, P.J. Gellings \\ Department of Chemical Technology, University of Twente, P.O. Box 217, 7500 AE Enschede, Netherlands
}

Received 24 November 1993

\begin{abstract}
Thin alumina films were deposited on stainless steel, type AISI 304. The deposition process was carried out in nitrogen with low partial pressures of water $\left(0-2.6 \times 10^{-2} \mathrm{kPa}(0-0.20 \mathrm{mmHg})\right)$ by metal-organic chemical vapour deposition (MOCVD) with aluminium-tri-sec-butoxide (ATSB) as the precursor. Also results are presented regarding the alumina deposition in the presence of small amounts of 2-butanol. The film properties, including the protection of the underlying substrate against aggressive gas compounds such as sulphur at high temperatures, the chemical composition, the microstructure, and the refractive index were investigated as a function of the water vapour pressure.

In contrast with the results of stress reduction in silica films by the addition of small amounts of water to the deposition process, no significant effect on the internal stress in alumina films was found. TEM analysis showed that extremely fine grains of $\gamma$ $\mathrm{Al}_{2} \mathrm{O}_{3} / \mathrm{AlO}(\mathrm{OH})$ were formed, in agreement with the refractive index. Only an increase of the $\mathrm{OH}$ groups was found if water was added to the process, which also was the only impurity in the oxide film. Carbon was not detected.
\end{abstract}

Keywords: Alumina films; Chemical properties; MOCVD

\section{Introduction}

The chemical vapour deposition (CVD) process will become a more and more useful technique for the application of thin solid films. For example, thin alumina films made by the decomposition of metal alkoxides are increasingly used as passivating dielectrics in silicon devices, for multilayer interference filters and as intermetal dielectrics [1-3]. Other applications are found in the field of protective coatings for solar cells $[4,5]$ and high-temperature applications [6].

Recently, much attention has been paid to the metalorganic chemical vapour deposition (MOCVD) of thin alumina films. For example, Duffy et al. [2], Dhanavantri et al. [3], Morssinkhof [6] and Aboaf [7] studied the deposition of thin alumina films from aluminium-tri-isopropoxide (ATI). Other precursors used were 2-ethylhexanoate (Maruyama and Nakai [8]), aluminium-acetylacetonate (Maruyama and Arai [9], Boldyrev et al. [10], Korzo [11]), and hexafluoroacetylacetonate (Temple and Reisman [12]).

* Corresponding author.
Previous papers [13-17] reported that alumina films suffer from internal stresses, due to thermal and growth stresses, which result in cracking and/or delamination of the alumina film. Therefore, more research is necessary to produce films with reduced stresses. This is reached by, amongst others, the formation of an intermediate oxide layer between the coating and the metal, and by a reduced deposition rate at high deposition temperatures. Also thermal annealing by a heat treatment afterwards may result in reduced stresses [16-19].

From the literature [18-24] it is known that the addition of small amounts of water to the deposition process can sometimes significantly reduce the internal stress in superficially applied thin oxide layers. Hofman [20] reported that the addition of small amounts of water during the deposition of silica resulted in a decreased crack density and a higher critical thickness of the coating before delamination took place. This effect was explained by a network-opening reaction where the $\mathrm{OH}$ groups can participate in bond-breaking and -forming. The $\mathrm{OH}$ groups formed this way may reduce the viscosity of the material and will, as a consequence, increase the stress relaxation by viscous flow. Brueckner 
[21,22] and Tomozawa [23] found, for example, that the viscosity of $\mathrm{OH}$-containing silica is much lower than of silica without $\mathrm{OH}$ groups. According to these results, the effect of the addition of water to the aluminium deposition process using aluminium-tri-sec-butoxide (ATSB) was investigated. A corresponding reaction between the $\mathrm{OH}$ groups and the alumina was suggested, which may significantly reduce the internal stress by an enhanced relaxation mechanism, as supposed by Desu $[18,19]$.

This study reports the deposition of thin alumina films by the pyrolytic decomposition of aluminium-trisec-butoxide (ATSB). In this paper the effect of small additions of water and 2-butanol to the MOCVD process is discussed. The alumina films have been deposited by the thermal decomposition of ATSB in nitrogen at atmospheric pressure. Material properties, such as the protection of steels against high-temperature corrosion, and chemical structure and composition were investigated as a function of the water concentration.

\section{Experimental details}

Alumina films were deposited by means of atmospheric-pressure MOCVD using aluminium-tri-secbutoxide (ATSB, Janssen Chimica) and dried nitrogen gas. The substrate used in the experiments was a stainless steel, type AISI 304, which was cut from an electropolished metal sheet and ultrasonically cleaned in, consecutively, RBS soap, hexane and ethanol.

A schematic diagram of the experimental set up is shown in Fig. 1. The ATSB is introduced into the furnace by passing nitrogen gas through the ATSB bubbler with an equilibrium vapour pressure of ATSB at $138^{\circ} \mathrm{C}$ of $0.13 \mathrm{kPa}(1.0 \mathrm{mmHg})$. The ATSB flow rate is adjusted by controlling the flux of nitrogen gas through the ATSB bubbler at atmospheric pressure. This gas mixture was added to the main nitrogen flow which enters the reaction chamber. To prevent condensation of the precursor, the equipment between the ATSB vessel and the reactor was heated to $160^{\circ} \mathrm{C}$. An extra compound $\left(\mathrm{H}_{2} \mathrm{O}\right)$ was added by using another bubbler. A drying tower was added to the system to remove any moisture present in the diluting gas.

Additional deposition experiments were performed with small amounts of 2-butanol with vapour pressures in the range between 0 and $0.026 \mathrm{kPa}(0-0.20 \mathrm{mmHg})$. The flow rate was controlled by using mass-flow controllers (Brooks type 5850TR and 5850E). The deposition reaction was carried out in a quartz tube with a diameter of $45 \mathrm{~mm}$. The uniform-temperature zone in the reactor was $120 \mathrm{~mm}$. The specimens were attached to a ceramic tube, parallel to the gas flow, with a thermocouple on the inside which is used to measure the substrate temperature and to control the furnace temperature. (Standard conditions were: substrate temperature, $330^{\circ} \mathrm{C}$; ATSB temperature, $138^{\circ} \mathrm{C}$; flow rate $6.51 \mathrm{~min}^{-1}$ (STP)). The

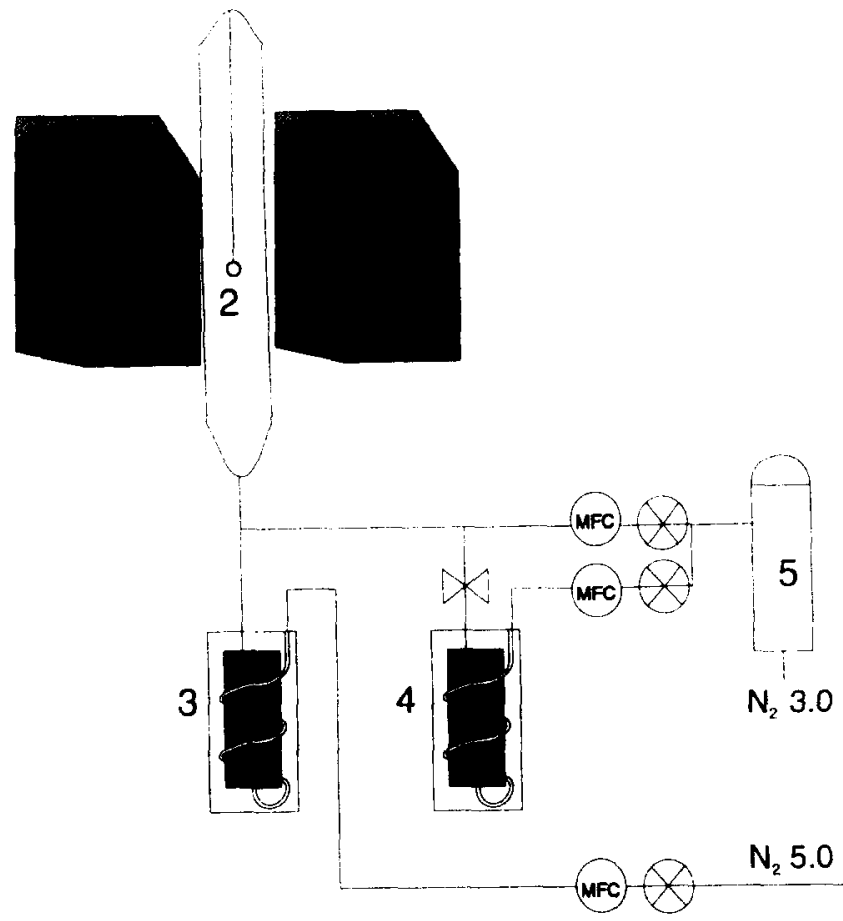

Fig. 1. Schematic view of the experimental MOCVD set-up: 1 , oven; 2 , thermocouple; 3 , precursor; 4 , water; 5 , drying tower.

deposition rate of the films on the metallic substrate was determined by weighing the samples before and after the deposition. In the experiments, specimens were used with alumina films of $0.20 \pm 0.05 \mathrm{mg} \mathrm{cm}^{-2}$.

Corrosion experiments were performed in order to investigate the protective capacity of the films against aggressive gas components such as oxygen and sulphur at high temperatures, and were carried out in a closed system for $24 \mathrm{~h}$. The system was first flushed with argon for $20 \mathrm{~h}$ with a flow rate of $161 \mathrm{~h}^{-1}$. The argon was saturated with water at $15{ }^{\circ} \mathrm{C}$. After this, a mixture of $5 \% \mathrm{H}_{2} \mathrm{~S} / 95 \% \mathrm{H}_{2}$ with a flow rate of $4 \mathrm{l} \mathrm{h}^{-1}$ was introduced in the argon flow. After $2 \mathrm{~h}$, in order to stabilize the flow, the furnace was heated to the test temperature $\left(450 \quad{ }^{\circ} \mathrm{C}\right)$. The whole system was flushed for another $2 \mathrm{~h}$ and then closed. No relevant difference in corrosion rate and corrosion products was obtained between a closed system and a system with a continuous flow, if the reactive gas consumption did not exceed $20 \%$.

The morphology and the composition of the corroded specimens were investigated by means of optical and scanning electron microscopes (JEOL M $35 \mathrm{CF}$ ), the latter equipped with an EDX analysis system (Kevex Delta, class III).

To characterize the chemical composition and the depth profile, the alumina films were analysed by means of a Perkin-Elmer PHI 600 scanning Auger multiprobe. Alternate sputtering and Auger analysis were used for in-depth analysis. The functional groups, including hydrogen-containing bonds within the films, were mea- 


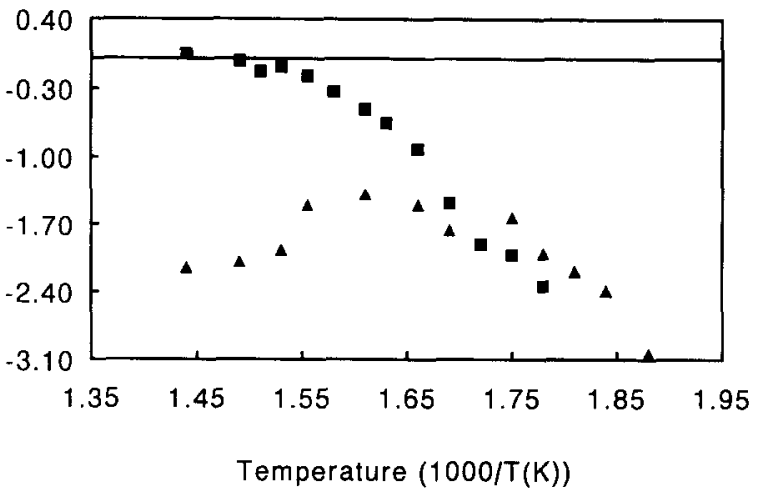

Fig. 2. Deposition rate of alumina as a function of the deposition temperature and water vapour pressure; $0 \mathrm{kPa}$ (squares), $0.017 \mathrm{kPa}$ (triangles).

sured by Fourier transform infrared spectroscopy (FTIR), using a Nicolet 20 SXB FTIR equipment. Owing to the non-transparency of the specimens, the spectrometer was equipped with a diffuse-reflection cell [9]. The microstructure of the films was investigated by X-ray diffraction (XRD), using a Philips PW 1710 X-ray diffractometer with monochromatic $\mathrm{Cu} K \alpha$ radiation, and a high-resolution transmission electron microscope (TEM), model JEOL $200 \mathrm{CX}$. The refractive index of

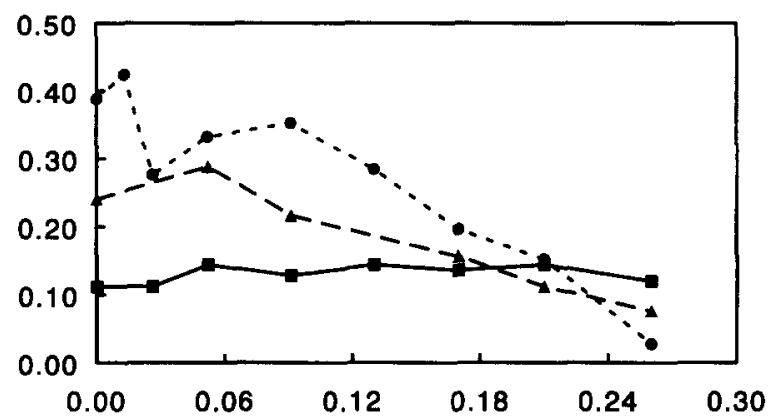

(a)

Vapour Pressure H2O (kPa)

\section{$(E-1)$}

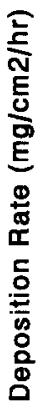

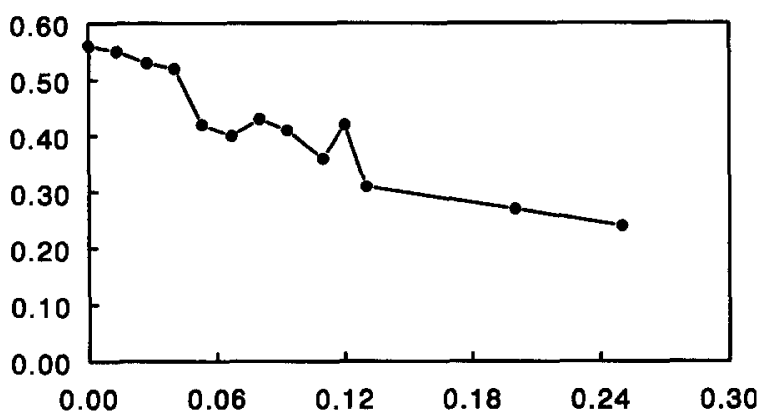

(b)

Vapour Pressure 2-butanol ( $\mathrm{kPa})$

$(E-1)$

Fig. 3. Deposition rate of alumina: (a) as a function of water vapour pressure at three different temperatures: $280^{\circ} \mathrm{C}$ (squares), $300^{\circ} \mathrm{C}$ (triangles), $330^{\circ} \mathrm{C}$ (circles); (b) as a function of 2-butanol vapour pressure (deposition temperature, $320^{\circ} \mathrm{C}$ ).
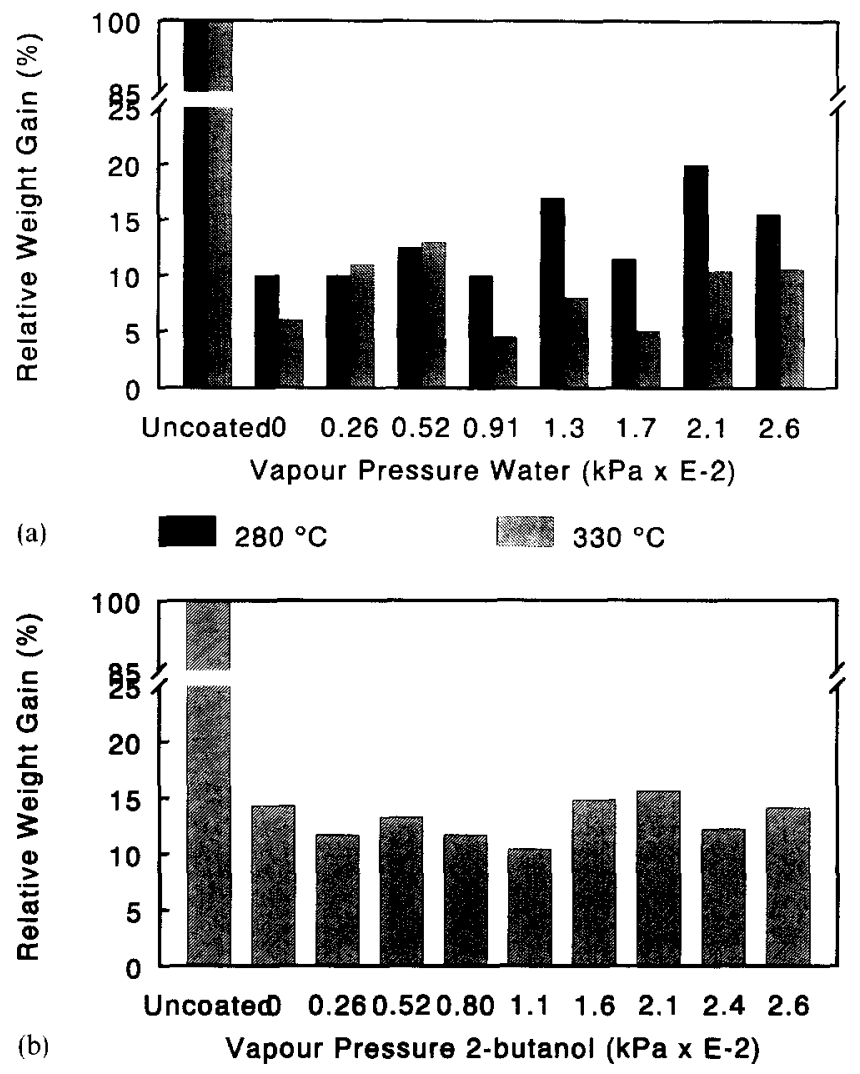

Fig. 4. Bar diagram of the relative weight gain $(\%)$ of the specimens (after $24 \mathrm{~h}$ of sulphidation at $450^{\circ} \mathrm{C}$ ): (a) as a function of vapour pressure of water and of deposition temperature; (b) as a function of vapour pressure of 2-butanol (deposition temperature, $320^{\circ} \mathrm{C}$ ).

the deposited films was measured with a Plasmos ellipsometer (type SD 2002) at a wavelength of $6328 \AA$ generated by a He-Ne laser source. The angle of incidence was $70^{\circ}$.

\section{Experimental results}

The rate of deposition of alumina on AISI 304 as a function of the temperature and water concentration is shown in Fig. 2. The experimental activation energy for the heterogeneous reaction without the addition of water is $83 \pm 5 \mathrm{~kJ}$ mole $^{-1}$. For the deposition reaction with a partial pressure of water of $1.7 \times 10^{-2} \mathrm{kPa}(0.13 \mathrm{mmHg})$, the experimental activation energy did not change significantly: $81 \pm 11 \mathrm{~kJ}^{\mathrm{mole}}{ }^{-1}$. This figure shows that a further increase in temperature results in a deposition rate less dependent of the temperature. If water was present, the growth rate decreased with higher deposition temperatures. Furthermore, the amount of interference rings significantly increased when water was added to the gas stream.

In addition, deposition experiments were performed in order to study the effect of changing water concentration on the deposition rate. The water vapour pressure 
in the system (reactor) was changed from 0 to $0.20 \mathrm{mmHg}$ $(0.026 \mathrm{kPa})$ at three deposition temperatures; 280,300 and $330^{\circ} \mathrm{C}$. The results are shown in Fig. 3(a). At $280^{\circ} \mathrm{C}$ no effect was observed if water was added to an amount up to $0.20 \mathrm{mmHg}(0.026 \mathrm{kPa})$. The deposition rate decreases at 300 and $330^{\circ} \mathrm{C}$ with increasing water vapour pressure. Fig. 3(b) shows the growth rate of alumina (deposition temperature, $320^{\circ} \mathrm{C}$ ) as a function of the vapour pressure of 2-butanol. Also here it is clear that the growth rate decreased with increasing amounts of 2-butanol.

To investigate the thin alumina films on cracks and pores, sulphidation experiments were performed in an hydrogen sulphide-containing gas atmosphere. After exposure times of $24 \mathrm{~h}$ the relative weight gain was high (more than 5\%). In Figs. 4(a) and 4(b) the relative weight gains are shown as a function of the water and 2-butanol concentration. No significant improvement of the protective capacity was obtained when water or 2-butanol was added to the gas stream. SEM observations show that, after depositions without water or at low water concentrations, besides cracks also small single-crystalline iron sulphide products are formed on the alumina film. These products seem to grow through the film, presumably owing to the presence of pores. Iron sulphide was also found on the cracks. At higher water concentrations (more than $0.10 \mathrm{mmHg}=$ $0.013 \mathrm{kPa}$ ) the amount of localized FeS crystallites was significantly reduced, indicative of an alumina film with increased density without pores. However, many cracks are still present. In Fig. 5, SEM pictures are shown of the sulphidized samples. For the alumina film deposited at $330^{\circ} \mathrm{C}$, it was found that the amount of single-crystal products decreased with increasing water content. At a deposition temperature of $420^{\circ} \mathrm{C}$, no difference of the surface morphology was observed, and thus no further function of the water concentration.

The composition and depth profiles of the deposited alumina films were analysed by Auger electron spectroscopy (AES) in conjunction with ion sputtering ( $44 \mathrm{~nm}$ $\min ^{-1}$ ). In Figs. 6(a) and 6(b) the steady-state Auger spectra (survey scans) are shown of the alumina films deposited with $0.13 \mathrm{mmHg}$ water vapour pressure at 330 and $400{ }^{\circ} \mathrm{C}$. Only for the films deposited at $400^{\circ} \mathrm{C}$ was some carbon detected on the outer surface of the film, which may be explained by adsorption of carbon dioxide from the atmosphere. After one or more sputtering cycles (one cycle corresponds to $1 \mathrm{~min}$ sputtering at a rate of

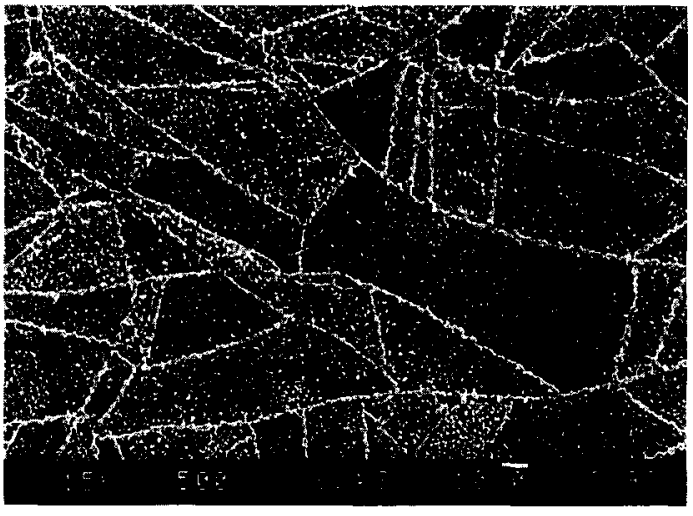

(a)

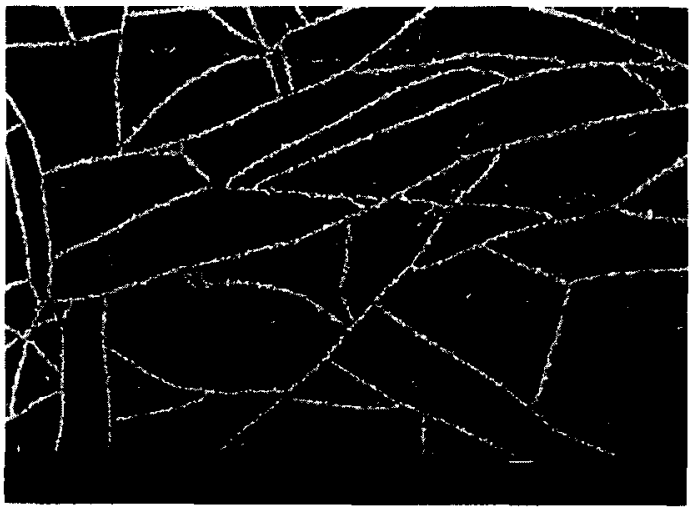

(c)

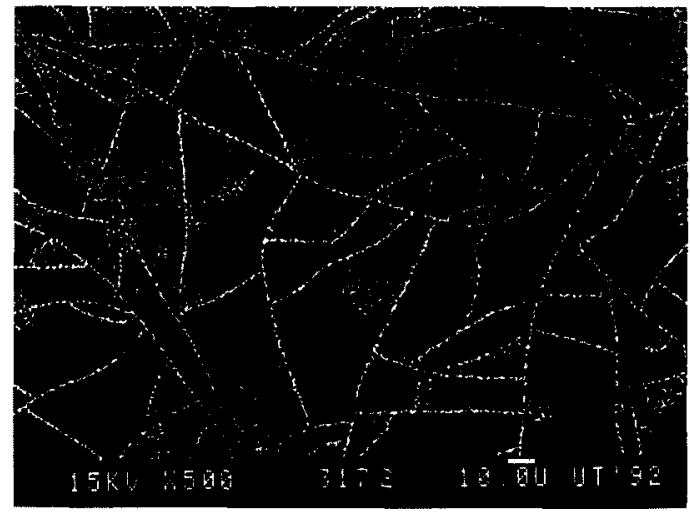

(b)

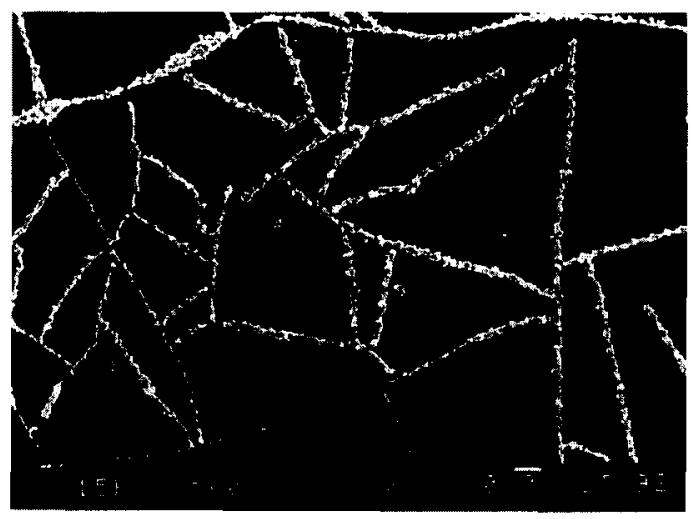

(d)

Fig. 5. SEM images of the surface morphology of coated samples after $24 \mathrm{~h}$ of sulphidation at $450{ }^{\circ} \mathrm{C}$ : (a) deposition temperature, $330{ }^{\circ} \mathrm{C}$, without water addition; (b) deposition temperature, $330^{\circ} \mathrm{C}$, with $0.013 \mathrm{kPa}\left(0.10 \mathrm{mmHg}\right.$ ) water pressure; (c) deposition temperature, $420^{\circ} \mathrm{C}$, without water addition; (d) deposition temperature, $420^{\circ} \mathrm{C}$, with $0.017 \mathrm{kPa}(0.13 \mathrm{mmHg})$ water pressure. 


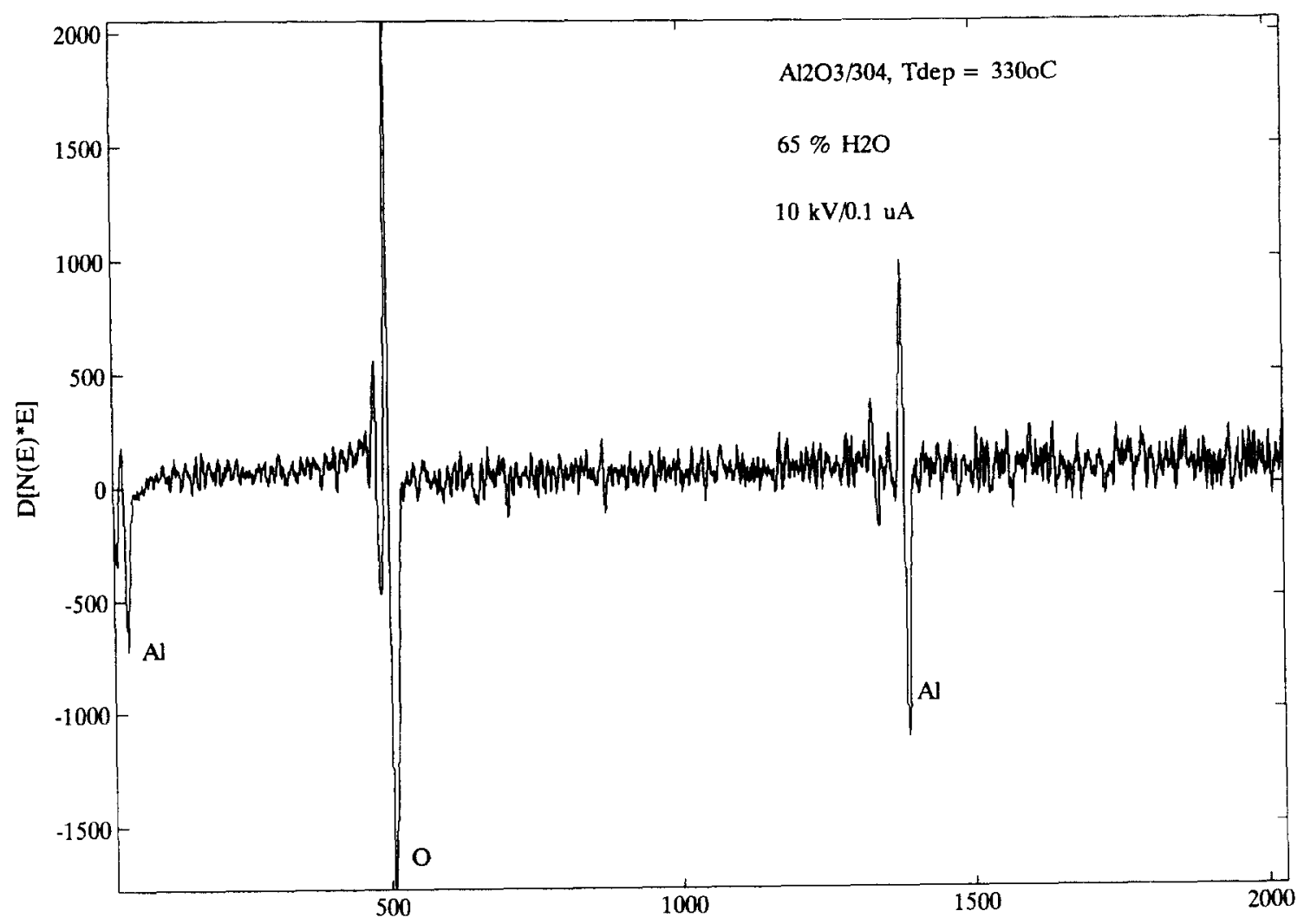

(a)

Electron Kinetic Energy (eV)

PHI

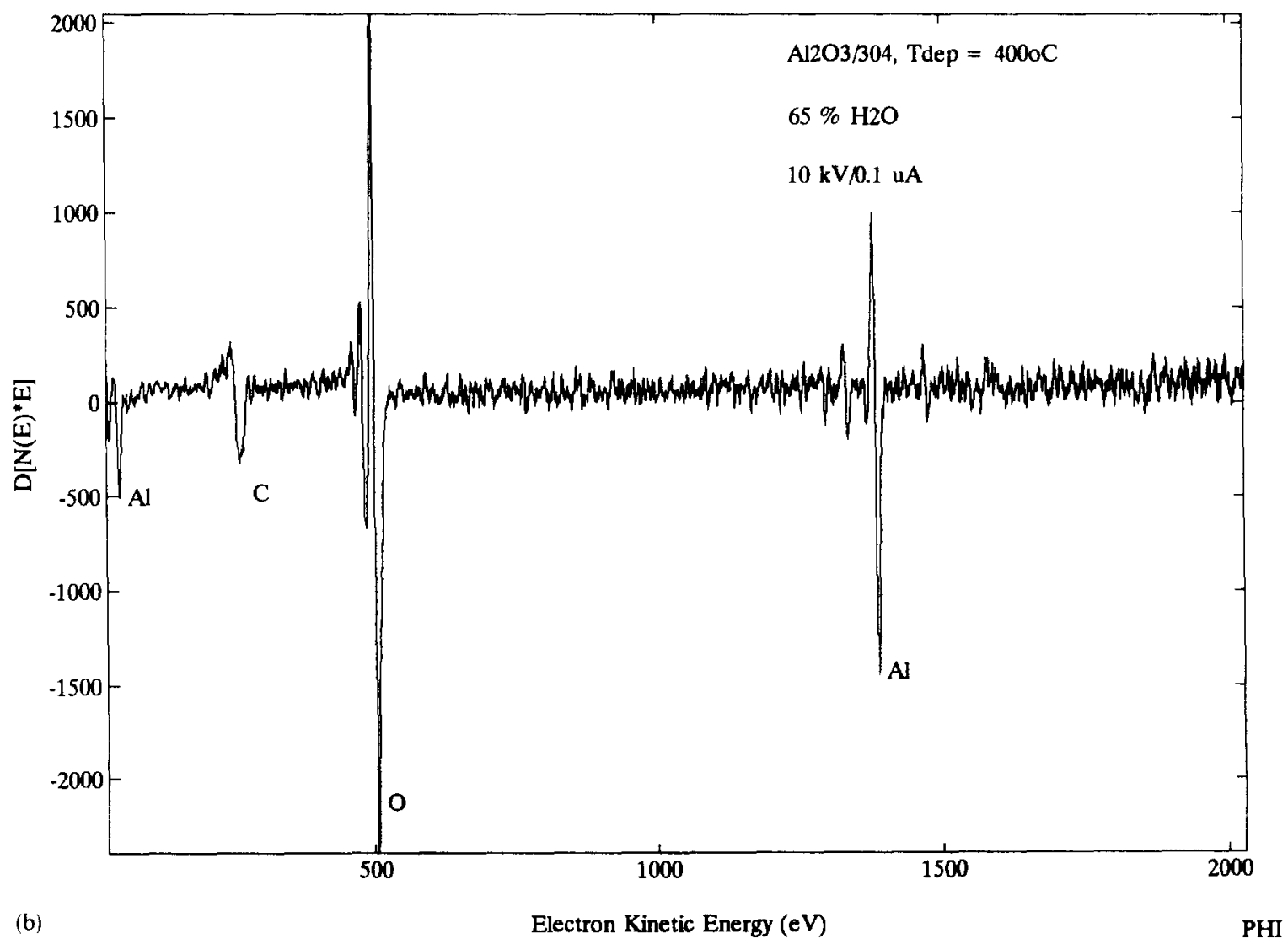

Fig. 6. AES survey scan of the outer surface of the alumina film, deposited with a water vapour pressure of $0.017 \mathrm{kPa}(0.13 \mathrm{mmHg}):(\mathrm{a})$ deposition temperature, $330^{\circ} \mathrm{C}$; (b) deposition temperature, $400^{\circ} \mathrm{C}$ 
$44 \mathrm{~nm} \min ^{-1}$ ) no carbon was detected in the alumina films, even for films deposited at temperatures as low as $290{ }^{\circ} \mathrm{C}$. Fig. 7 shows the AES depth profile of the sample with a thickness of about $0.6 \mu \mathrm{m}$; the peak-to-peak height is shown as a function of the sputter depth. This corresponds well with earlier experiments $[15,16]$ which showed that alumina films deposited in a nitrogen atmosphere also did not contain any carbon.

FTIR was used to identify functional groups such as $\mathrm{H}-\mathrm{O}$ and $\mathrm{Al}-\mathrm{O}$ groups. In Figs. 8(a) and 8(b) the infrared absorption spectra are shown of the alumina films deposited at 280 and $330{ }^{\circ} \mathrm{C}$ with different water concentrations in the gas phase. The broad absorption bands at $500-1100 \mathrm{~cm}^{-1}$ represent the vibration of $\mathrm{Al}_{2} \mathrm{O}_{3}$ [8,14-16], and the absorption bands at 1050-1100 and $3200-3400 \mathrm{~cm}^{-1}$ the $\mathrm{C}-\mathrm{O}$ and $\mathrm{H}-\mathrm{O}$ bond vibrations, respectively. The vibration characteristics of $\mathrm{H}-\mathrm{O}$ lie between 1250 and $2000 \mathrm{~cm}^{-1}$ and between 400 and $700 \mathrm{~cm}^{-1}$. From this figure, the specific absorbance bands with wave numbers of $900-950 \mathrm{~cm}^{-1}$ and $3000-3700 \mathrm{~cm}^{-1}$ were detected, indicative of the $\mathrm{Al}-\mathrm{O}$ $\left(\mathrm{Al}_{2} \mathrm{O}_{3}\right.$ vibrations) and $\mathrm{H}-\mathrm{O}$ bond vibrations, respectively. Furthermore, it was found that at $0.017 \mathrm{kPa}$ $(0.13 \mathrm{mmHg})$ water vapour pressure the deposition temperature affects the shape and peak position of the absorption bands. With increasing deposition temperature the $\mathrm{H}-\mathrm{O}$ IR absorption band decreases in intensity. The vibration band of $\mathrm{Al}_{2} \mathrm{O}_{3}$ becomes sharper, and shifts from $900 \mathrm{~cm}^{-1}$ at low deposition temperatures to about $940 \mathrm{~cm}^{-1}$ at higher deposition temperatures. In Fig. 9(a) the IR absorption spectra are shown as a function of the deposition temperature (all depositions were carried out with $0.017 \mathrm{kPa}(0.13 \mathrm{mmHg})$ water vapour). These results correspond well with those obtained from $\mathrm{Al}_{2} \mathrm{O}_{3}$ deposition under a pure nitrogen atmosphere without any additions.

Figs. 10(a)-10(d) show the transmission electron micrographs of the alumina films deposited under standard conditions (without water (Figs. 10(a),10(b), and with $0.017 \mathrm{kPa}(0.13 \mathrm{mmHg})$ water vapour pressure (Figs. 10(c),10(d))). In Fig. 10(a) very fine grains are observed, the size being between 12 and $20 \mathrm{~nm}$. Fig. 10(b) shows the electron diffraction pattern of this sample. For the alumina film, deposited in the presence of a small amount of water, no significant changes were found. The grain size of this alumina film is almost equal to the alumina film deposited under pure nitrogen, as shown in Fig. 10(c). Also from the diffraction pattern (Fig. 10(d)), it is calculated that the grain sizes did not differ very much. As a result, it was found that in both

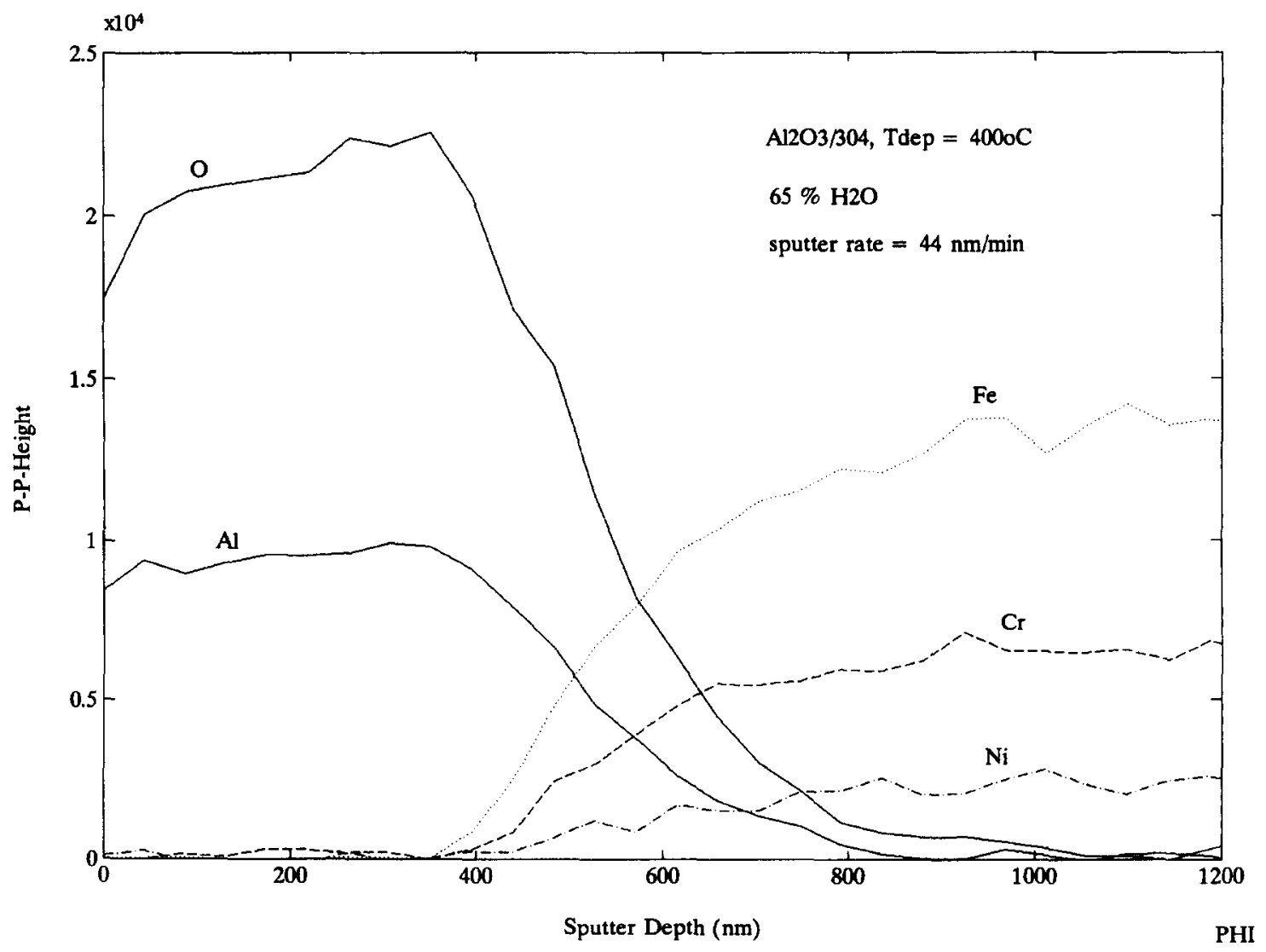

Fig. 7. AES depth profile of the alumina film, deposited with $0.017 \mathrm{kPa}(0.13 \mathrm{mmHg})$ water vapour pressure at $400{ }^{\circ} \mathrm{C}$ 


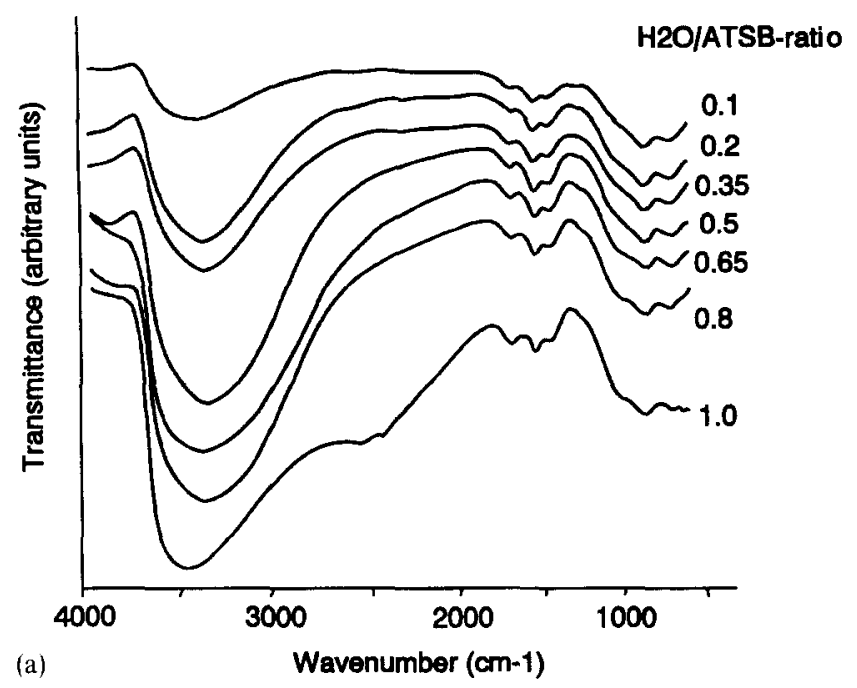

(a)

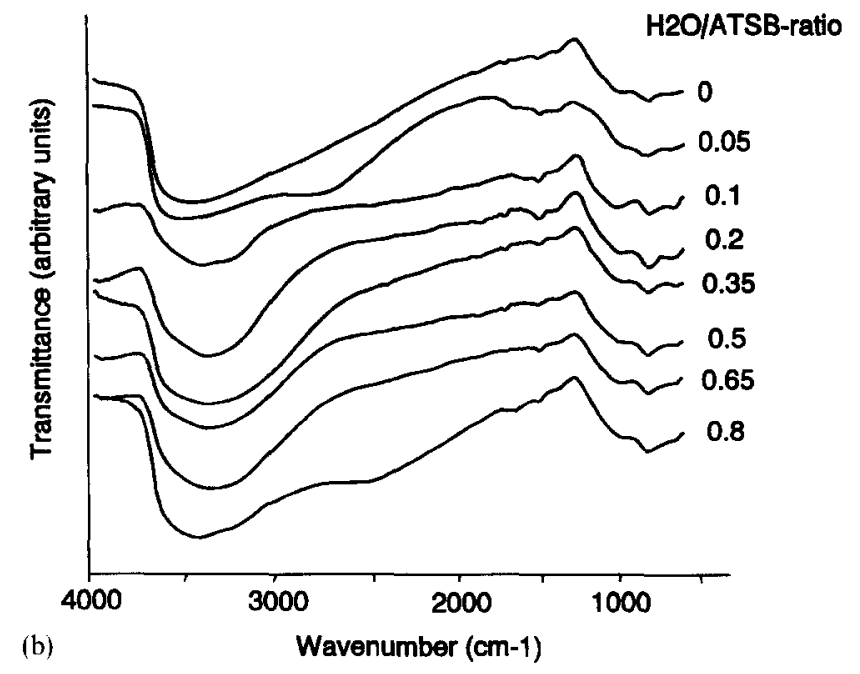

Fig. 8. FTIR absorption spectra of the alumina films as a function of the water vapour pressure: (a) deposition temperature, $280^{\circ} \mathrm{C}$; (b) deposition temperature, $330^{\circ} \mathrm{C}$.

cases the alumina film contains $\gamma-\mathrm{Al}_{2} \mathrm{O}_{3}$ and $\mathrm{AlO}(\mathrm{OH})$. In order to compare these results with the deposition of $\mathrm{SiO}_{2}[20]$, additional TEM analyses were performed.

Fig. 11(a) shows the small grains of $\mathrm{SiO}_{2}$ (deposited without water at $560^{\circ} \mathrm{C}[20]$ ) with sizes between 10 and $18 \mathrm{~nm}$. Electron diffraction patterns indicative of nanocrystalline phases were found here also. Figs. 11(c) and 11 (d) show the silica film and the corresponding electron diffraction patterns where the silica film has been deposited with addition of water. Here also, no significant changes in the grain sizes were found if water was added to the gas stream. The electron diffraction rings with a more diffuse pattern imply a more amorphous structure of the oxide. From these figures it is clear that the two oxide films, silica and alumina, did not differ very much regarding the grain sizes.

The refractive indices were measured with a Plasmos ellipsometer and are shown in Fig. 12. In this figure the
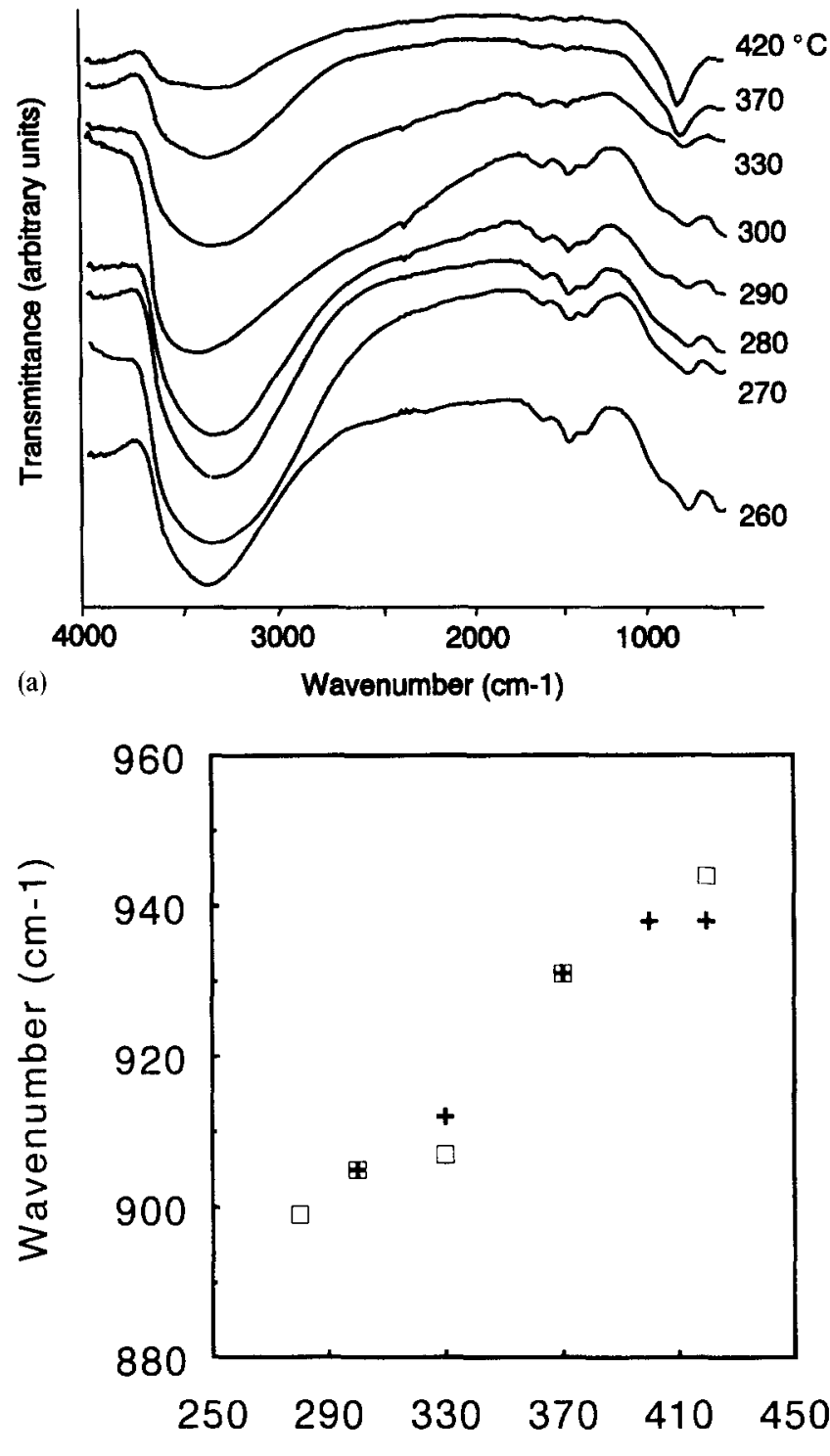

(b)

\section{Deposition Temperature $\left({ }^{\circ} \mathrm{C}\right)$}

Fig. 9. (a) FTIR absorption spectra of the alumina films as a function of the deposition temperature (water vapour pressure, $0.017 \mathrm{kPa}$ $(0.13 \mathrm{mmHg})$ ); (b) peak position of the $\mathrm{Al}-\mathrm{O}$ bond, obtained from the FTIR absorption spectra at $0 \mathrm{kPa}$ (crosses) and $0.017 \mathrm{kPa}$ (squares).

refractive index is given as a function of the water concentration, and changes from 1.56 to 1.63 when the water concentration changed from 0 to $0.017 \mathrm{kPa}$, which corresponds well with the value for amorphous alumina [15].

\section{Discussion}

The addition of small amounts of water during the deposition process for the production of thin films can significantly reduce the internal stress and improve the chemical and mechanical properties of the thin oxide 


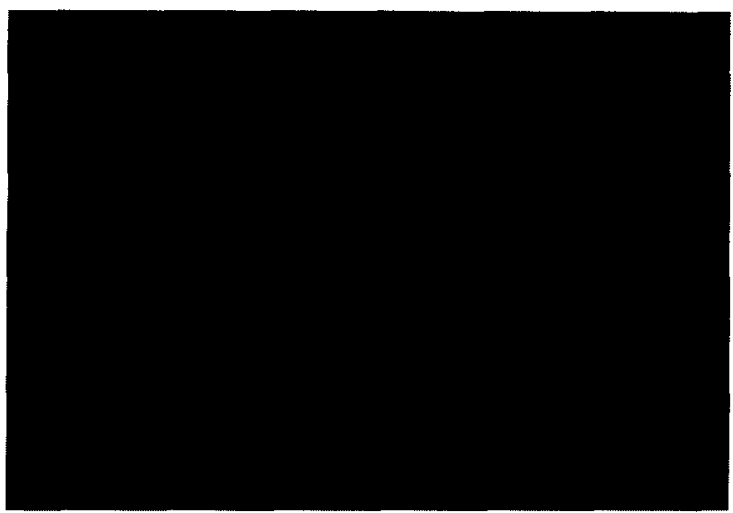

(a)

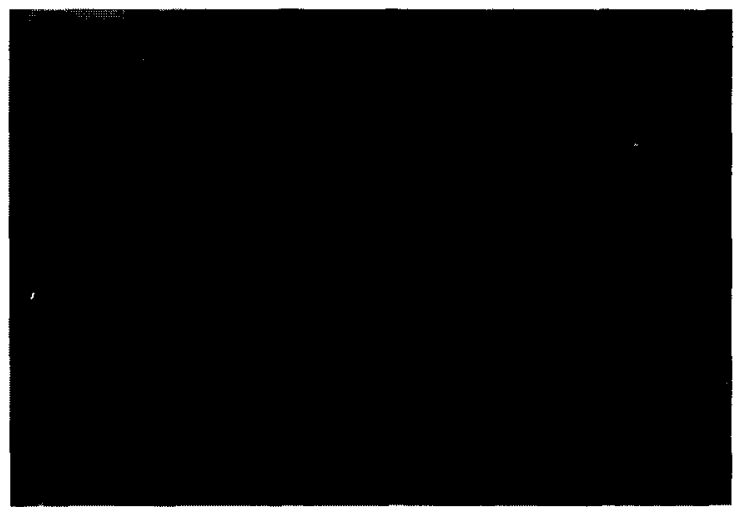

(c)

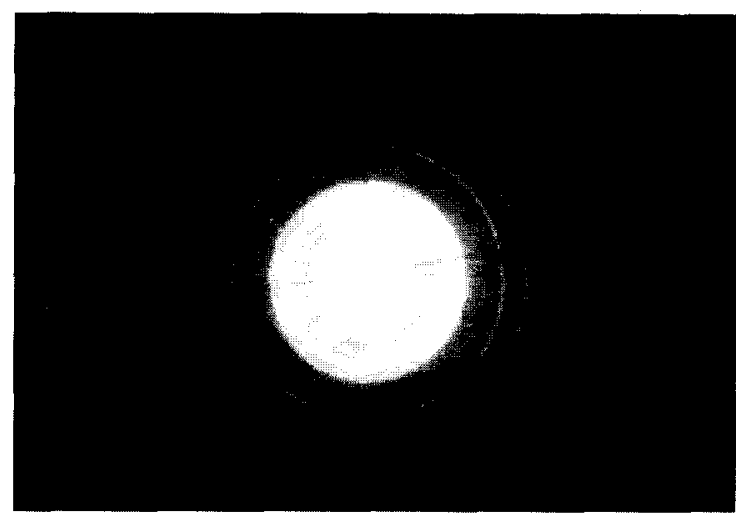

(b)

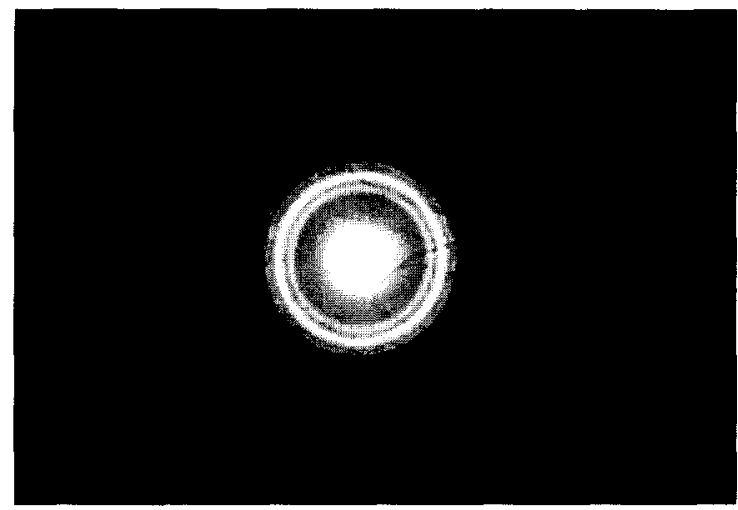

(d)

Fig. 10. TEM images (magnification, $250000 \times$ ) of alumina films: (a) deposited without water; (b) diffraction ring pattern corresponding to (a); (c) with $0.017 \mathrm{kPa}$ water vapour pressure; (d) diffraction ring pattern corresponding to (c).

films. Besides these effects, the kinetics also are affected by the addition of water. To obtain more information on the effect of the partial pressure of water, the deposition rate of alumina was also measured as a function of the partial pressure of water between 0 and $2.67 \times 10^{-2} \mathrm{kPa}$ ( 0 and $0.20 \mathrm{mmHg}$ ). At temperatures up to $280^{\circ} \mathrm{C}$, no effect was observed, but from $300^{\circ} \mathrm{C}$ the deposition rate decreased linearly with the water vapour. At very low levels of water vapour, some scattering in the deposition rate occurred, probably owing to the inaccuracy of the mass-flow controllers used. The effect of thermal and hydrolytic decomposition of aluminum alkoxides can be explained by the reactions proposed by Schulman et al. [25]:

$$
\begin{aligned}
& 2 \mathrm{Al}(\mathrm{OR})_{3} \rightarrow \mathrm{Al}(\mathrm{OH})_{3}+3 \mathrm{ROH}+3 \text { olefins } \\
& \mathrm{Al}(\mathrm{OR})_{3} \rightarrow \mathrm{Al}_{2} \mathrm{O}_{3}+3 \mathrm{H}_{2} \mathrm{O}+6 \text { olefins } \\
& \mathrm{Al}(\mathrm{OR})_{3}+3 \mathrm{H}_{2} \mathrm{O} \rightarrow \mathrm{Al}_{2} \mathrm{O}_{3}+3 \mathrm{ROH}+3 \text { olefins } \\
& \mathrm{Al}(\mathrm{OR})_{3} \rightarrow \mathrm{Al}(\mathrm{OH})_{3}+3 \text { olefins } \\
& \mathrm{Al}(\mathrm{OR})_{3}+3 \mathrm{H}_{2} \mathrm{O} \rightarrow \mathrm{Al}(\mathrm{OH})_{3}+3 \mathrm{ROH} \\
& \mathrm{ROH} \rightarrow \mathrm{H}_{2} \mathrm{O}+\text { olefin } \\
& 2 \mathrm{Al}(\mathrm{OH})_{3} \rightarrow \mathrm{Al}_{2} \mathrm{O}_{3}+3 \mathrm{H}_{2} \mathrm{O}
\end{aligned}
$$

During the first step of the thermal decomposition of the aluminium alkoxide, reactions (1),(2),(4),(6) and (7) are the most important ones with alumina as the main product. Water, which is one of the reaction products, is now available for further hydrolysis of the alkoxide, and can form alcohol, as given by reactions (3) and (5). Morssinkhof [6] reported that if more water is formed, even under pure nitrogen conditions, it results in an increased partial pressure of water in the reactor, and thus may play an important role in the deposition of $\mathrm{Al}_{2} \mathrm{O}_{3}$.

The number of water molecules produced by the pyrolytic decomposition of ATSB has a negligible effect on the decomposition of the ATSB compared with the effect of added water. If water is added to the process stream, it is assumed that reactions (3) and (5) become more important, especially at higher temperatures. The same results were found by Bradley [26] and Baryshnikov et al. [27], who reported that the water reacts effectively with the original alkoxide under the formation of the corresponding alcohol. The hydrolysis process is localized mainly in the gas phase and is accompanied by the formation of $\mathrm{Al}_{2} \mathrm{O}_{3}$ and $\mathrm{AlO}(\mathrm{OH})$. This means that the amount of precursor available for 


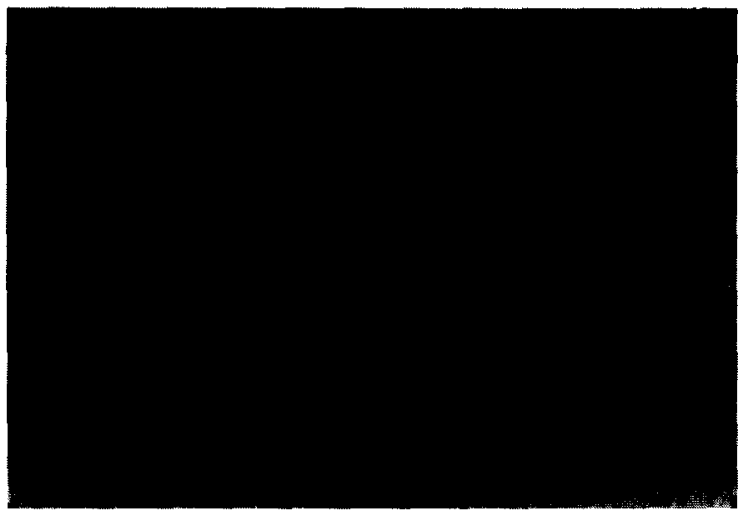

(a)

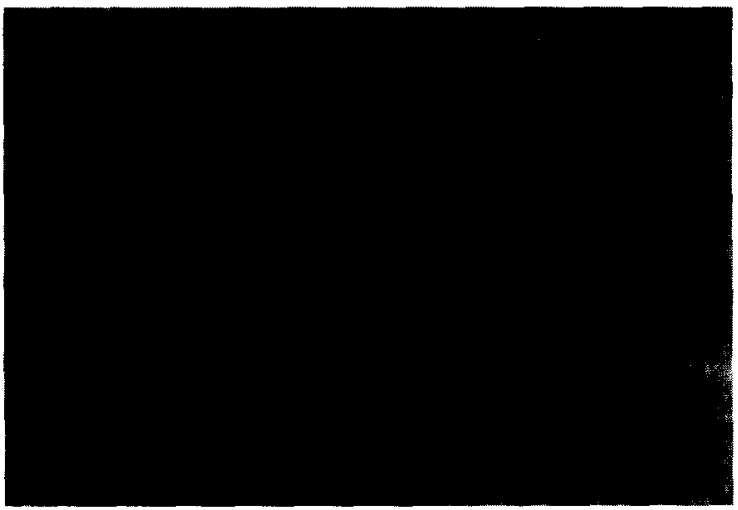

(c)

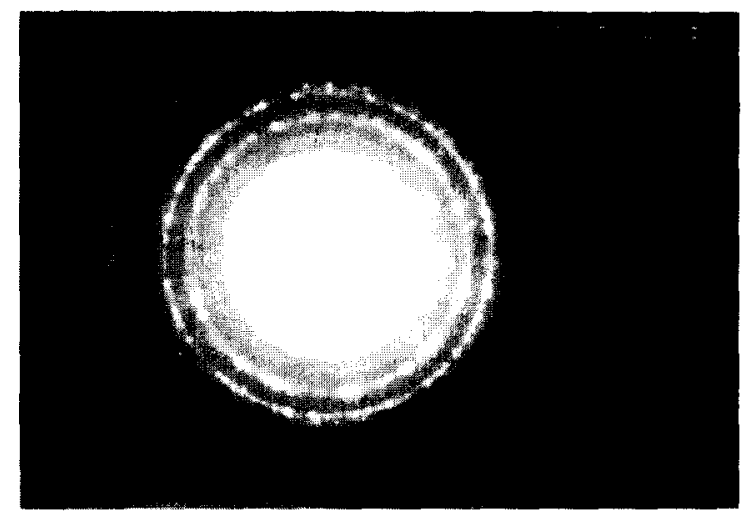

(b)

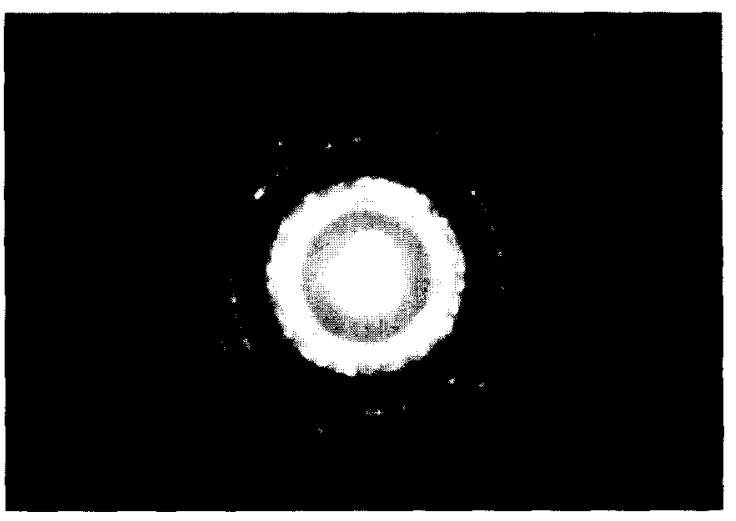

(d)

Fig. 11. TEM images (magnification, $250000 \times$ ) of silica films: (a) deposited without water: (b) diffraction ring pattern corresponding to (a); (c) with $6.5 \times 10^{-3} \mathrm{kPa}$ water vapour pressure; (d) diffraction ring pattern corresponding to (c) [20].

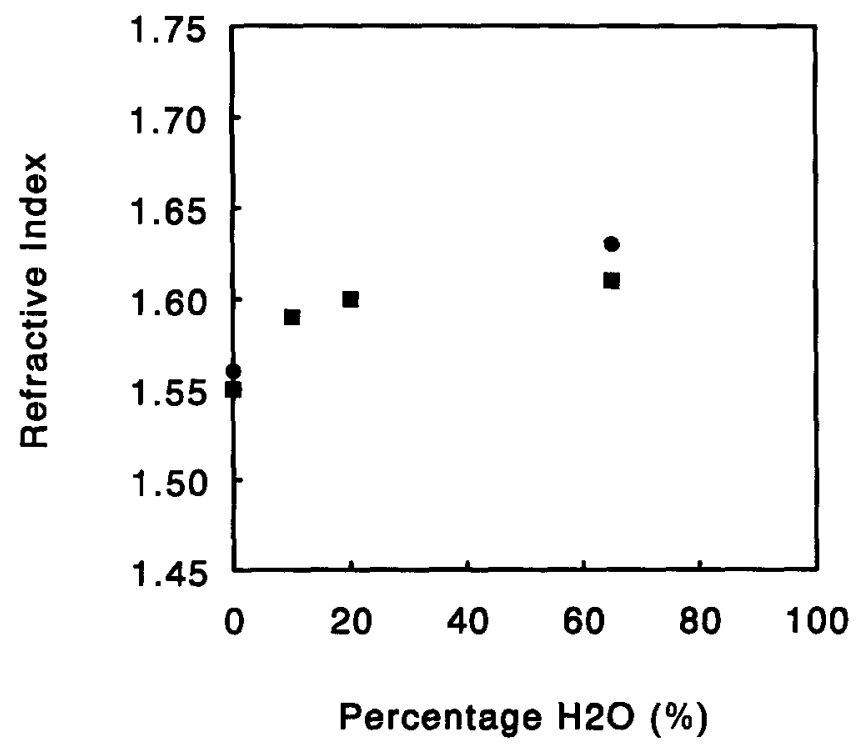

Fig. 12. Index of refraction of the alumina films deposited on AISI 304 as a function of the water vapour pressure at $330^{\circ} \mathrm{C}$ (squares) and $400{ }^{\circ} \mathrm{C}$ (circles).

the deposition of alumina is reduced by the interaction between ATSB and water, and to a minor extent due to the homogeneous pyrolytic reaction forming $\mathrm{Al}_{2} \mathrm{O}_{3}$ and
$\mathrm{Al}(\mathrm{OH})_{3}$. The effect of the latter occurs at temperatures higher than needed for the hydrolytic reaction. This means that the conversion of the aluminium alkoxide to the oxide uses parallel reaction paths, following the simple reaction scheme

$\mathrm{ATSB}-\Delta \mathrm{T} \rightarrow \mathrm{Al}_{2} \mathrm{O}_{3}+\mathrm{Al}(\mathrm{OH})_{3}$

+ products (heterogeneous)

$\mathrm{ATSB}-\Delta \mathrm{T} \rightarrow \mathrm{Al}_{2} \mathrm{O}_{3}+\mathrm{Al}(\mathrm{OH})_{3}$

+ products (homogeneous)

ATSB $+3 \mathrm{H}_{2} \mathrm{O}-\Delta \mathrm{T} \rightarrow \mathrm{Al}_{2} \mathrm{O}_{3}+$ products (homogeneous)

$\mathrm{ATSB}+3 \mathrm{H}_{2} \mathrm{O}-\Delta \mathrm{T} \rightarrow \mathrm{Al}(\mathrm{OH})_{3}$

+ products (homogeneous)

where at low deposition temperatures reaction $(8)$ is more important. At higher deposition temperatures reactions (9)-(11) also take part in the overall decomposition process, and become more pronounced with increasing temperature.

As already mentioned, the presence of oxidizing compounds leads to a lower cracking temperature of the alkoxide molecules. This effect was also found by Aboaf 
[7], who investigated the deposition of alumina from aluminium-tri-isopropoxide. Owing to the presence of oxidizing compounds, in this case $\mathrm{O}_{2}$, the alkoxide starts to decompose around $250^{\circ} \mathrm{C}$ in oxygen, and around $270^{\circ} \mathrm{C}$ in nitrogen.

Deposition experiments with small additions of 2-butanol were based on the results from Morssinkhof [6]. Addition of the corresponding alcohol, in this case 2-propanol, to the gas stream with aluminium-triisopropoxide reduced the growth rate and improved the uniformity. From Fig. 3(b) it is clear that here also the growth rate is reduced with increasing vapour pressure of 2-butanol. The thickness uniformity and the corrosion protective capacity were not improved. Therefore, no additional methods of analysis and characterization were performed.

It is well known [28] that alumina serves as an effective diffusion barrier against aggressive compounds such as oxygen and sulphur. Problems arise if the alumina contains fast diffusion paths such as pores and cracks, as shown previously [13-16], where pore- and crack-free alumina films were not obtained. The underlying metallic substrate can then easily react with the aggressive compounds, forming corrosion products. As a consequence, fast degradation of the material causes a considerable reduction of the lifetime. The exposure of the coated specimens to sulphidizing atmospheres is an easy and fast method of determining the presence of these fast diffusion paths. From the weight gain measurements it is clear that the alumina films deposited with small amounts of water vapour in the gas phase do not show any significant improvement regarding protection against high-temperature corrosion.

From the SEM pictures (Fig. 5), two different corrosion products were distinguished: single-crystalline and chain-like products. Addition of water has only a small beneficial effect regarding the single-crystalline products, which are reduced when the water or 2-butanol vapour pressure in the gas phase is increased. Nevertheless, both corrosion products can still be found on the surface. Only when the deposition temperature is increased do the single-crystalline corrosion products almost disappear [29], which corresponds with previous results [15] from alumina deposition in pure nitrogen. This corresponds well with the results of Barybin and Tomilin [30] and Sladek and Gibert [31], who reported that an increasing deposition temperature improves the homogeneity and decreases the porosity of the coatings.

The single-crystalline corrosion products are related to the presence of pores, and the chain-like products to the presence of stress in the film. This means that the addition of water will only reduce the pores, and will have no effect on the amount of cracks due to the presence of internal stress.

Sladek and Gibert [31] found that the removal of the bulky alkoxide groups in the deposited film resulted in holes and yielded a highly strained amorphous oxide of low density. Our results did not confirm this conclusion because no carbon was detected in the alumina film. This means that no alcohol or other alkoxide groups were incorporated in the film during the deposition process.

From the FTIR analyses it was confirmed that the $\mathrm{OH}$ band became more pronounced with increasing water content, indicative of more $\mathrm{OH}$ groups into the oxide film. A similar increase in the amount of $\mathrm{OH}$ groups was also found by Sladek and Gibert [31] and Herron [32]. The oxide films deposited by CVD from metal alkoxides and water were characterized by the production of hydroxides. Further attack of $\mathrm{H}_{2} \mathrm{O}$ on the alkoxide groups, proceeding on or in the growing film, thus leads to a replacement of the bulky alkoxide groups by the hydroxide groups. This reaction can also occur to a smaller extent in pure nitrogen, because water is formed as a reaction product from the pyrolytic decomposition of the ATSB molecules.

The aim of this study was to reduce the internal stress and to obtain a uniform thickness of the thin oxide films. It was shown before [13-16,20] that MOCVDapplied thin oxide films such as alumina and silica suffer from high internal stresses, resulting in cracking and delamination, which occur after a critical thickness. Hofman [20] found that the intrinsic stress caused by the deposition process was significantly reduced if water was added to the process stream.

Quantification of the internal stress in silica films from the growth process and/or from the difference in thermal expansion was reported previously by Desu $[18,19]$. The film stress was related to the distortions in the $\mathrm{Si}-\mathrm{O}-\mathrm{Si}$ angles and was discussed in relation to changes in the FTIR spectra, i.e. peak positions. It was found that the $\mathrm{Si}-\mathrm{O}-\mathrm{Si}$ stretching band in the FTIR spectra showed a positive shift and the $\mathrm{Si}-\mathrm{O}-\mathrm{Si}$ bending band showed a negative shift after annealing at high temperatures, corresponding to a reduction in the tensile stress. This means that the film stress can indirectly be quantified by the peak positions of the stretching and bending bands. Therefore, it is now assumed that, for the Al-O band also, changes in stress could be manifested by a shift of the peak positions of the characteristic bands. Thus, if the addition of water results in a reduction of the intrinsic stress, a shift of the peak position will occur. It was found before [15] that the absorbance bands around $900-950 \mathrm{~cm}^{-1}$ (Al-O band) increased in intensity and shift towards higher wavenumbers with higher deposition temperatures. This was also observed for the deposited alumina films with $0.017 \mathrm{kPa}(0.13 \mathrm{mmHg})$ water vapour pressure, see also Fig. 9(b). From this figure it is clear that water did not affect the peak position of the FTIR bands. Additional experiments showed that at a fixed deposition temperature the wavenumber of the $\mathrm{Al}-\mathrm{O}$ band did not change with increasing 
water vapour pressure. This is in contrast with the results of Hofman [20], where the FTIR spectra showed a slight shift of the stretching band of $\mathrm{SiO}_{2}$ towards the higher frequencies and of the bending band towards lower frequencies, which corresponds well with the results of Desu $[18,19]$, indicative of a reduced stress. Hofman [20] also found that the $\mathrm{Si}-\mathrm{OH}$ peak increased in intensity with increasing water content.

In the case of alumina, no shift was found if the water was added to the gas stream; only the $\mathrm{O}-\mathrm{H}$ band was more pronounced. Therefore it is assumed that, according to the FTIR spectra, the stress in the film is almost unaffected. If stress reduction in the film occurred, the crack density should be reduced, which was not observed in the corrosion experiments. This also indicates that no significant stress reduction was obtained by the addition of small amounts of water.

Stress relaxation in the silica films was explained by the lowering of the activation energy for viscous flow. Owing to this lower activation energy, the relaxation time will decrease significantly, indicative of a smaller viscosity of the film. The mechanism of the reduction in viscosity is assumed to be based on the increased $\mathrm{OH}$ concentration in the silica film [18,19,21-23]. Brueckner $[21,22]$ and Tomozawa [23] found that $\mathrm{OH}$-containing silica showed a viscosity about two orders of magnitude less than dry $\mathrm{SiO}_{2}$. It was suggested that the hydroxide groups can participate in the bond-breaking and bondforming following the reversible reaction:

$\mathrm{Si}-\mathrm{OH}+\mathrm{HO}-\mathrm{Si} \leftrightarrows \mathrm{Si}-\mathrm{O}-\mathrm{Si}+\mathrm{H}_{2} \mathrm{O}$

Thus, the more $\mathrm{OH}$ groups are present, the easier the stress relaxation. This mechanism was also assumed for the alumina films as a hypothetical approach for stress reduction. If $\mathrm{OH}$ groups were incorporated into the film, the following reversible reaction could be assumed

$\mathrm{O}=\mathrm{Al}-\mathrm{OH}+\mathrm{HO}-\mathrm{Al}=\mathrm{O} \leftrightarrows \mathrm{O}=\mathrm{Al}-\mathrm{O}-\mathrm{Al}=\mathrm{O}+\mathrm{H}_{2} \mathrm{O}$

Therefore, it is suggested that, in spite of the fact that the bond strength for diatomic molecules, often known as the bond dissociation energy $\mathrm{D}(\mathrm{R}-\mathrm{X})$, for $\mathrm{O}-\mathrm{Al}$ is much lower than for the $\mathrm{O}-\mathrm{Si}\left(449 \mathrm{~kJ}\right.$ mole ${ }^{-1}$ and 790 mole $^{-1}$, respectively), reaction (12) will take place much faster than reaction (13). Probably the presence of groups such as $\mathrm{Si}-\mathrm{OH}$ or $\mathrm{Si}=\mathrm{O}$ can have a catalytic effect on the reaction: this in contrast with groups containing $\mathrm{Al}$ as the metal.

Also the difference in chemical structure between silica and alumina may partly explain the difference in stress relaxation. The chemical structure of alumina is based on a regular polycrystalline lattice structure, whereas the structure of silica is based on an irregular glassy network. During the stress relaxation or deformation of alumina, each grain should rotate so that the active slip directions become more or less parallel to the axis of tension, with the result that the grains become elongated in the direction of the flow. Deformation of polycrystalline materials thus involves an appreciable movement along grain boundaries as well as along slip planes. Stress relaxation in silica by viscous flow may take place by changing the bond angles and bond distances between $\mathrm{Si}$ and $\mathrm{O}$, and by rupture of a certain amount of $\mathrm{Si}-\mathrm{O}$ bonds. Owing to this stress relaxation mechanism, the activation energy for deformation of the silica films may be much lower than the activation energy for the deformation of alumina.

Summarizing, it can be said that the addition of small amounts of water to the deposition process described in this paper did not allow stress relaxation of the metalorganic chemical-vapour-deposited alumina films. Only the porous structure of the films was affected by this addition; cracks remained to be found on the surface. More research is required to optimize the MOCVD process in order to obtain a dense, pore- and crack-free alumina film.

\section{Conclusions}

Stress reduction in silica films was caused by small additions of water to the deposition process. This was based on an increased viscous flow in the amorphous silica by breaking and bonding of the $\mathrm{Si}-\mathrm{O}$ bonds by $\mathrm{H}_{2} \mathrm{O}$, forming silanol groups. Small amounts of water were also used for the metal-organic chemical vapour deposition of an alumina film. From corrosion experiments it was observed that no significant stress reduction was obtained. Only the porosity of the film was slightly reduced. Neither was significant improvement of the crack and pore reduction obtained by using small amounts of 2-butanol.

From TEM analysis it was determined that the alumina films have a very fine grain size $(12-20 \mathrm{~nm})$ of polycrystalline $\gamma-\mathrm{Al}_{2} \mathrm{O}_{3} / \mathrm{AlO}(\mathrm{OH})$. This size was not affected by addition of small amounts of water. The refractive index of the film slightly increased with increasing amounts of water from 1.56 to 1.63 , which corresponds with the value of amorphous alumina.

FTIR spectra showed that the number of $\mathrm{OH}$ groups increased with increasing water vapour pressure, which was found as the only impurity. Carbon was not detected above the background level of the AES spectra.

\section{Acknowledgments}

This research was supported by the Innovative Research Program on Technical Ceramics (IOP-TK) with financial aid from the Dutch Ministry of Economic Affairs. Thanks are due to G. J. M. Weierink for the 
FTIR measurements, A. H. J. van den Berg (CMO) for the AES experiments, K. Eijkel (MESA) for the ellipsometry measurments, and to T. Kachlicki (CMO) for the TEM analysis (all at the University of Twente, Netherlands), and to G. Verspui and C. Visser (both from Philips, Eindhoven, Netherlands) for valuable discussions.

\section{References}

[1] R.S. Ehle, B.J. Baliga and W. Katz, J. Electron. Mater. 12 (3) (1983) 587

[2] M.T. Duffy, J.E. Carnes and D. Richman, Metall. Trans., 2 (1971) 667.

[3] C. Dhanavantri, R.N. Karekar and V.J. Rao, Thin Solid Films, $127(1985) 85$.

[4] I.T. Richie and B. Window, Appl. Opt., 16 (1977) 1438.

[5] D.M. Jrotter and A.J. Sievers, Appl. Opt., 19 (1980) 711

[6] R.W.J. Morssinkhof, The deposition of thin alumina films on steels by MOCVD, Ph.D. Thesis, University of Twente, Netherlands, 1991.

[7] J.A. Aboaf, J. Electrochem. Soc., 114 (1967) 948.

[8] T. Maruyama and T. Nakai, Appl. Phys. Lett., 58 (19) (1991) 2079.

[9] T. Maruyama and S. Arai, Appl. Phys. Lett., 60 (3) (1992) 322.

[10] V.P. Boldyrev, V.M. Koleshko, B.S. Reznikov, I.V. Nekaryukin, L.D. Buika and K.D. Yashin, Neorg. Mater., 12 (12) (1976) 1783.

[11] V.F. Korzo, Zh. Prikl. Khim., 49 (1) (1975) 74.

[12] D. Temple and A. Reisman, J. Electron. Mater., 19 (9) (1990) 995.

[13] V.A.C. Haanappel, H.D. van Corbach, T. Fransen and P.J. Gellings, Cracking and delamination of metal-organic chemical vapour deposited alumina and silica films, Mater. Sci. Eng., A167 (1993) 179.

[14] V.A.C. Haanappel, H.D. van Corbach, T. Fransen and P.J. Gellings, Corrosion-resistant coatings (alumina) produced by metal-organic chemical vapour deposition using aluminiumtri-sec-butoxide, Thin Solid Films, 230 (1993) 138.

[15] V.A.C. Haanappel, H.D. van Corbach, T. Fransen and P.J. Gellings, Properties of alumina films prepared by atmospheric-pressure metal-organic chemical vapour deposition (MOCVD), Surf. Coat. Technol., 63 (1994) 145.

[16] V.A.C. Haanappel, H.D. van Corbach, T. Fransen and P.J. Gellings, The effect of thermal annealing on the properties of alumina films prepared by atmospheric-pressure metal organic chemical vapour deposition (MOCVD), Surf. Coat. Technol., 64 (1994) 183.

[17] F.C. Eversteijn, Philips Res. Rep., 21 (1966) 379.

[18] S.B. Desu, J. Am. Ceram. Soc., 72 (1989) 1615.

[19] S.B. Desu, Jpn. J. Appl. Phys., 30 (1991) L2123.

[20] R. Hofman, The protection of alloys against high temperature corrosion by $\mathrm{SiO}_{2}$ coatings, Ph.D. Thesis, University of Twente, Netherlands, 1993.

[21] R. Brueckner, J. Non-Cryst. Solids, 5 (1970) 123.

[22] R. Brueckner, J. Non-Cryst. Solids, 5 (1970) 176.

[23] M. Tomozawa, J. Non-Cryst. Solids, 73 (1985) 197.

[24] J.B. Rem, Graduate Paper, University of Twente, Netherlands, 1993.

[25] G.P. Schulman, M. Trusty and J.H. Vickers, Thermochim. Acta, 85 (1963) 907.

[26] D.C. Bradley, Chem. Rev., 89 (1989) 1317.

[27] Y.Y. Baryshnikov, I.L. Zakharov and G.I. Makin, Zh. Obshch Khim., 60 (6) (1990) 1350

[28] P. Kofstad, High Temperature Corrosion, Elsevier, London, 1988

[29] W.A. Pliskin, J. Vac. Sci. Technol., 14 (5) (1977) 1064.

[30] A.A. Barybin and V.I. Tomilin, Zh. Prikl. Khim., 49 (1976) 1699.

[31] K.J. Sladek and W.W. Gibert, Proc. Eur. Congr. on CVD, 1972, p. 215.

[32] H.M. Herron, M.S. Thesis, University of Texas at Austin, TX, 1971. 